Revista Brasileira de Agricultura Irrigada v.11, nº.1, p. 1145 - 1154, 2017

ISSN 1982-7679 (On-line)

Fortaleza, CE, INOVAGRI - http://www.inovagri.org.br

DOI: 10.7127/rbai.v11n100553

Protocolo 553.17 - 19/01/2017 Aprovado em 20/02/2017

\title{
ADAPTAÇÃO DE GENÓTIPOS DE ALFACE CRESPA EM CONDIÇÕES SEMIÁRIDAS
}

Geraldo Milanez de Resende ${ }^{1}$, Nivaldo Duarte Costa ${ }^{2}$, Jony Eshi Yuri ${ }^{1}$, José Hortêncio Mota ${ }^{3}$

\section{RESUMO}

A alface (Lactuca sativa L.) é a hortaliça folhosa mais importante na dieta da população brasileira. Entre os tipos cultivados destaca-se a de folha crespa como a mais consumida. Objetivou-se nesse trabalho avaliar o comportamento de cultivares de alface crespa nos períodos de maio a julho de 2013 e abril a julho de 2014, em Petrolina-PE. O delineamento experimental utilizado foi de blocos ao acaso com seis genótipos em 2013 (Amanda, Bruna, Vanda, Isabela, CAP/CR/77-1 e 10Y3104-1) e em 2014 (Bruna, Coral, Cristal, 10Y3090-2, SVR2005 e 10Y3134-2), com quatro repetições. Em termos de massa fresca por planta e produtividade em 2013 sobressaíram os genótipos Vanda (400 g planta ${ }^{-1}$ e 49,1 t ha ${ }^{-1}$ ), CAP/CR/77-1 (367 g planta ${ }^{-1}$ e 47,9 t ha ${ }^{-1}$ ), Bruna (365 g planta-1 e 44,8 t ha ${ }^{-1}$ ) e Amanda (345 g planta $^{-1}$ e 42,3 $\mathrm{t} \mathrm{ha}^{-1}$ ). Em 2014, maior massa fresca por planta e produtividade foram alcançadas pelos genótipos 10Y3164-2 (418 $\mathrm{g}$ planta $^{-1}$ e 51,5 t ha $\left.{ }^{-1}\right), 10 \mathrm{Y3090}-2$ (410 g planta $^{-1}$ e 50,4 t ha ${ }^{-1}$ ), Bruna (398 g planta $^{-1}$ e 48,9 t ha ${ }^{-1}$ ) e SVR-2005 (391 g planta ${ }^{-1}$ e 48,2 t $\left.\mathrm{ha}^{-1}\right)$. O número médio de folhas variou entre 23,5 e 30,1 folhas planta ${ }^{-1}$ e entre 26,8 e 30,8 folhas para os anos de 2013 e 2014, respectivamente. Por ocasião da colheita não se observou nenhuma incidência de pendoamento precoce entre os genótipos. Os ciclos vegetativos foram de 62 e 61 dias para os anos de 2013 e 2014, respectivamente.

Palavras-chave: Lactuca sativa, rendimento, competição, massa fresca por planta, correlação canônica.

\section{ADAPTATION OF CRISPLEAF LETTUCE GENOTYPES AT SEMI-ARID CONDITIONS}

\footnotetext{
ABSTRACT

The lettuce (Lactuca sativa L.) is the most important leafy vegetable in the diet of the Brazilian population. Among the types of lettuce grown there is the crisp lettuce as the most consumed. This study aimed to evaluate the behavior of cultivars of crisp lettuce in PetrolinaPE, Brazil, in the period of May to July of 2013 and from April to July of 2014. The

1 Autor para correspondência Eng. Agrônomo, D.Sc., Embrapa - Centro de Pesquisa Agropecuária do Trópico Semiárido.e-mails: geraldo.milanez@embrapa.br; jony.yuri@embrapa.br

2 Eng. Agrônomo, M.Sc., Embrapa - Centro de Pesquisa Agropecuária do Trópico Semiárido. E-mail: nivaldo.costa@embrapa.br

${ }^{3}$ Eng. Agrônomo, D.Sc., Universidade Federal de Goiás/Campus Jataí; e-mail: hortencio.mota@terra.com.br
} 
experimental design was a randomized complete block with six genotypes in 2013 (Amanda, Bruna, Vanda, Isabela, CAP/CR/77-1 e 10Y3104-1) and 2014 (Bruna, Coral, Cristal, 10Y3090-2, SVR2005 e 10Y3134-2), with four replications. The fresh mass per plant and yield showed significant differences between treatments in 2013, standing out the Vanda (400 g plant ${ }^{-1}$ and $40.0 \mathrm{t} \mathrm{ha}^{-1}$ ), CAP/CR/77-1 (367 g plant ${ }^{-1}$ and $36.7 \mathrm{t} \mathrm{ha}^{-1}$ ), Bruna (365 g plant ${ }^{-1}$ and $36.5 \mathrm{t} \mathrm{ha}^{-1}$ ) and Amanda (345 g plant $\mathrm{t}^{-1}$ and $34.5 \mathrm{t} \mathrm{ha}^{-1}$ ). In 2014, the largest fresh mass per plant and yield were obtained by genotypes 10Y3164-2 (418 $\mathrm{g}^{-1 a n t^{-1}}$ e $\left.51.5 \mathrm{t} \mathrm{ha}^{-1}\right)$, 10Y30902 (410 g plant ${ }^{-1}$ e 50.4 t ha $^{-1}$ ), Bruna (398 g plant ${ }^{-1}$ e 48.9 t ha $^{-1}$ ) and SVR-2005 (391 g plant ${ }^{-1}$ e $48.2 \mathrm{t} \mathrm{ha}^{-1}$ ), without differ. The average number of leaves in genotypes ranged between 23.50 and 30.08 leaves plant ${ }^{-1}$ and between 26.8 and 30.8 leaves plant $^{-1}$ for the years 2013 and 2014, respectively. At harvest no incidence of bolting between genotypes was observed. The vegetative cycles were 62 and 61 days for the year 2013 and 2014, respectively.

Keywords: Lactuca sativa, yield, competition, fresh matter per plant, canonical correlation.

\section{INTRODUÇÃO}

De origem mediterrânica, a alface (Lactuca sativa) é a hortaliça folhosa mais importante no Brasil e no mundo, sendo consumida, principalmente, in natura na forma de saladas (SALA; COSTA, 2012), constituindo-se na mais popular, dentre aquelas em que as folhas são consumidas cruas e ainda frescas (COMETTI et al., 2004), sendo também importante do ponto de vista social, já que é cultivada, tradicionalmente, por pequenos produtores (BOAS et al., 2004).

A produção brasileira de alface, em 2006, foi de 576.338 toneladas, sendo o estado de São Paulo e Rio de Janeiro os maiores produtores, respondendo por $37,4 \%$ e $24,9 \%$ da produção, respectivamente. A alface responde por $11,7 \%$ da produção de hortaliças no Brasil (4,908 milhões de toneladas). A região Nordeste é responsável pela produção de 55.841 t, ou seja, aproximadamente $9,7 \%$ do total cultivado no Brasil, destacando-se como maiores produtores os estados do Ceará e Pernambuco (IBGE, 2016). Além disto, ao contrário dos sistemas de produção americano e europeu, que contam com excelente sistema logístico ligado à cadeia de frio, o modelo brasileiro baseia-se na produção de alface em "cinturões verdes", próximos aos centros consumidores (SALA; COSTA, 2012).

Atualmente existe uma grande diversidade de cultivares de alface no mercado, que explora diferenças nos formatos, tamanhos e cores das plantas. Ryder (1999) propôs uma classificação de acordo com as diferenças no formato e tamanho das folhas, no grau de sobreposição das mesmas e na formação ou não da cabeça. Por outro lado, a cor, o tipo de caule e outros possíveis caracteres possuem pouca influência nesta categorização. Assim, segundo este autor, existem seis tipos de alface: americana (crisphead), aspargo ou caule (stem), crespa (leaf), lisa (butterhead), romana (cos) e oleaginosa (oilseed). Desses tipos, o mais consumido é a alface crespa (SALA; COSTA, 2012; TRANI et al., 2016). De acordo com HORTBRASIL (2013), a participação da alface crespa tem dominado o mercado nos últimos dez anos, no entanto, reduzindo de $56 \%$ em 2002 para 51\% em 2012.

É uma planta bastante influenciada por condições ambientais, de modo que Sanders (2017) afirma que a cultura é adaptada a temperaturas amenas, sendo que a ideal para o desenvolvimento está na faixa de 15,5 e 18,3 ${ }^{\circ} \mathrm{C}$, apesar de tolerar temperaturas entre 26,6 e $29,4{ }^{\circ} \mathrm{C}$, por alguns dias, desde que as temperaturas noturnas sejam mais baixas. Temperaturas na faixa de 21,1 a $26,6{ }^{\circ} \mathrm{C}$, por longos períodos, promovem a elongação do caule (pendoamento) e prejudicam a formação de cabeças comerciais. A temperatura máxima tolerável fica em torno de $30{ }^{\circ} \mathrm{C}$ para a maioria das cultivares (DUARTE et al., 1992), sendo a variação ótima para a cultura entre 4 a $27{ }^{\circ} \mathrm{C}$ (PUIATTI; FINGER, 2005).

Gualberto et al. (2009) estudando o desempenho produtivo, a adaptabilidade e a estabilidade fenotípica de cultivares de alface 
do grupo crespa, em três épocas de plantio, no sistema hidropônico NFT, verificaram que as cultivares Deyse e Verônica foram as únicas a mostrarem adaptabilidade a todos ambientes estudados para produtividade e massa fresca da parte aérea. Entretanto, todas as demais cultivares apresentaram instabilidade para as características de produção, evidenciando que há intensa variação de comportamento em relação ao ambiente que são submetidas, e a importância de se avaliar em condições locais de cultivo.

Araújo et al. (2007) avaliando as cultivares Hortência, Mônica SF1 e Verônica, obtiveram massa fresca por planta variando entre 136,7 e 157,3 g, número de folhas entre 12,8 a 13,2; e produtividade entre 21,6 a 25,2 t ha $^{-1}$, sugerindo a cultivar Verônica como a mais recomendada para plantio. Segundo os autores temperatura do ar no local oscilou entre $24,4{ }^{\circ} \mathrm{C}$ e $31,5{ }^{\circ} \mathrm{C}$. Contudo, avaliando diferentes cultivares no inverno/primavera, Suinaga et al. (2013) verificaram que os maiores valores médios de massa fresca de planta foram apresentados pelas cultivares Vanda e Verônica, enquanto o maior diâmetro foi observado pela cultivar Solaris. As cultivares Itapuã, Vanda e Verônica exibiram as maiores estimativas de altura de plantas, no entanto, a cultivar Elba produziu o maior número de folhas comerciais.

Considerando a forma de produção nacional de alface, nota-se a importância de se avaliar as cultivares em condições locais às quais serão plantadas em larga escala quanto à produtividade e características comerciais (RODRIGUES et al., 2008). Nesse contexto, objetivou-se avaliar o desempenho produtivo de cultivares de alface, do segmento varietal crespa, nas condições do Submédio do Vale do São Francisco.

\section{MATERIAL E MÉTODOS}

Os experimentos foram conduzidos nos períodos de maio a julho de 2013 e abril a julho de 2014, em Petrolina-PE ( $9^{\circ} 9^{\prime}$ S, 40 $29^{\circ}$ 'W, 365,5 m de altitude). Segundo a classificação climática de Köppen, a região apresenta clima do tipo BSWh', semiárido. A temperatura média do ar varia de 24,1 a $28,0{ }^{\circ} \mathrm{C}$; as temperaturas máxima e mínima oscilam entre 29,6 a $34,0{ }^{\circ} \mathrm{C}$ e de 18,2 a $22,1{ }^{\circ} \mathrm{C}$, respectivamente. A umidade relativa do ar nos meses mais úmidos que correspondem àquelas do período chuvoso, variam em média de $66 \%$ a 73\%. Os menores valores ocorrem nos meses de setembro e novembro, abaixo de 55\%, coincidindo com o período mais quente do ano.

A precipitação média é de $549 \mathrm{~mm}$. O período chuvoso concentra-se entre os meses de novembro a abril, com $90 \%$ dos totais anuais, sendo que os meses de janeiro a abril, contribuem com $70 \%$ do total anual, destacando-se o mês de março e o de agosto como o mais e o menos chuvoso. Para velocidade do vento, os valores mais elevados ocorrem no período seco, entre os meses de agosto a outubro, chegando a $3,0 \mathrm{~m} \mathrm{~s}^{-1} \mathrm{com}$ menores valores no período chuvoso com média de $1,6 \mathrm{~m} \mathrm{~s}^{-1}$ no mês de março. A insolação anual é superior a 3.000 h (TEIXEIRA, 2010).

O solo foi classificado como Latossolo Vermelho Amarelo Distróferrico (SANTOS et al., 2006). Os dados climatológicos relativos às temperaturas médias foram de 24,1 e $22,2{ }^{\circ} \mathrm{C}$, com mínima em 19,1 e $17,2{ }^{\circ} \mathrm{C}$ e máxima de 30,3 e $27,9^{\circ} \mathrm{C}$, umidade relativa de 59,8 e 61,4 \% e baixa precipitação acumulada nos anos de $2013(9,9 \mathrm{~mm})$ e $2014 \quad(10 \mathrm{~mm})$, respectivamente. O solo foi classificado como Latossolo Vermelho Amarelo Distróferrico (SANTOS et al., 2006), apresentou nos anos de 2013 e 2014, respectivamente, as seguintes características químicas: $\mathrm{pH}\left(\mathrm{H}_{2} \mathrm{O}\right)=6,2$ e 6,1; $\mathrm{Ca}=2,2$ e $2,1 \mathrm{cmol}_{\mathrm{C}} \mathrm{dm}^{-3} ; \mathrm{Mg}=0,7$ e $0,7 \mathrm{cmol}_{\mathrm{c}}$ $\mathrm{dm}^{-3} ; \mathrm{K}=0,71$ e $0,69 \mathrm{cmol}_{\mathrm{c}} \mathrm{dm}^{-3} ; \mathrm{Al}=0,00 \mathrm{e}$ $0,01 \mathrm{cmol}_{\mathrm{C}} \mathrm{dm}^{-3}$, P(Mehlich) $=66,0$ e $67,1 \mathrm{mg}$ $\mathrm{dm}^{-3}$ e M.O. = 25,1 e 26,0 $\mathrm{g} \mathrm{kg}^{-1}$ e físicas (\%): areia $=83$; silte $=10$ e argila $=7$.

O delineamento experimental utilizado foi de blocos ao acaso, com seis genótipos em 2013 (Amanda, Bruna, Vanda, Isabela, CAP/CR/77-1 e 10Y3104-1) e seis genótipos em 2014 (Bruna, Coral, Cristal, 10Y3090-2, SVR2005 e 10Y3134-2), e quatro repetições.

O semeio das cultivares foi realizado em 21/05/2013 e 28/04/2014, em bandejas de 
isopor contendo 288 células, preenchidas com substrato comercial "Plantmax HT". As mudas foram conduzidas em viveiro durante 28 dias (2013) e 25 dias (2014), quando então foram transplantadas para o campo. O preparo do solo constou de aração, gradagem e levantamento dos canteiros a $0,20 \mathrm{~m}$ de altura.

As parcelas experimentais constituíramse de canteiros com quatro linhas de 2,0 m de comprimento espaçadas de $0,25 \mathrm{~m}$, sendo entre plantas de 0,25 m, perfazendo uma área de 2,0 $\mathrm{m}^{2}$. As duas linhas centrais formaram a área útil $\left(0,75 \mathrm{~m}^{2}\right)$, retirando-se uma planta em cada extremidade (doze plantas).

As adubações com base na análise do solo foram adaptadas de Trani (2016) e constaram da aplicação de $6,0 \mathrm{~kg} \mathrm{ha}^{-1}$ de $\mathrm{N}$ e 21,0 kg de $\mathrm{P}_{2} \mathrm{O}_{5} \mathrm{ha}^{-1}$ no plantio, utilizando-se superfosfato simples e uréia. Em cobertura, via fertirrrigação, foram adicionados $38 \mathrm{~kg} \mathrm{ha}^{-1}$ de $\mathrm{N}, 26,0 \mathrm{~kg} \mathrm{ha}{ }^{-1}$ de Ca; $60 \mathrm{~kg} \mathrm{ha}^{-1}$ de $\mathrm{P}_{2} \mathrm{O}_{5}$ e 40 $\mathrm{kg} \mathrm{ha}^{-1}$ de $\mathrm{K}_{2} \mathrm{O}$, aplicados três vezes por semana, até os 25 dias do transplantio, usandose como fontes de nutrientes a uréia, nitrocálcio, MAP e cloreto de potássio.

Nos dois anos de cultivo foram realizadas capinas manuais para o melhor desenvolvimento da cultura e irrigações através do método de microaspersão, com turno de dois dias e lâminas de água em torno de 9-10 mm, calculada em função da evaporação do tanque classe A. Os tratos fitossanitários realizados conforme recomendação de Filgueira (2008).

As colheitas foram realizadas aos 34 e 36 dias após o transplante nos anos de 2013/14, respectivamente; quando as plantas apresentaram-se completamente desenvolvidas, sendo avaliadas a massa fresca da planta ( $\mathrm{g}$ planta $^{-1}$ ); produtividade em $\mathrm{t} \mathrm{ha}^{-1}$ (expressa em área util de plantio), número de folhas por planta, comprimento e largura das folhas $(\mathrm{cm})$, comprimento do caule $(\mathrm{cm})$ e porcentagem de pendoamento na colheita. Os dados coletados foram submetidos à análise de variância, utilizando-se o teste $\mathrm{F}$ para comparação dos quadrados médios a 5\% de probabilidade e as médias foram comparadas pelo teste de ScottKnott, a 5\% de probabilidade (Sisvar, v. 5,3).

Além disso, foram obtidas, ainda, estimativas das correlações canônicas (CRUZ; REGAZZI, 2001) estatisticamente significativa, ao nível de $5 \%$ pelo teste F (SAS Institute, v. 9,2). Considerou-se os dados originais observados, para verificar as associações existentes entre um primeiro grupo de características produtivas (massa fresca e produtividade) com um segundo grupo formado pelas características morfológicas (número de folhas, comprimento e largura da folha e comprimento do caule). Dessa forma, foi possível determinar 2 funções canônicas ou 2 pares de variáveis estatísticas canônicas.

\section{RESULTADOS E DISCUSSÃO}

Foram observadas diferenças significativas para todas as características avaliadas, à exceção para largura da folha no plantio de 2013 (Tabela 1).

Tabela 1. Massa fresca por planta, número, comprimento e largura das folhas e comprimento do caule de genótipos de alface crespa. Petrolina - PE, 2013/2014.

\begin{tabular}{|c|c|c|c|c|c|}
\hline \multirow[b]{2}{*}{ Cultivares } & \multirow{2}{*}{$\begin{array}{c}\text { Massa } \\
\text { fresca } \\
\left.\text { (g planta }^{-1}\right)\end{array}$} & \multirow{2}{*}{$\begin{array}{l}\text { Número de } \\
\text { folhas }\end{array}$} & \multicolumn{2}{|c|}{ Folhas (cm) } & \multirow{2}{*}{$\begin{array}{l}\text { Comprimento } \\
\text { do caule }(\mathrm{cm})\end{array}$} \\
\hline & & & Comprimento & Largura & \\
\hline \multicolumn{6}{|c|}{ Ano de 2013} \\
\hline Vanda & $400 \mathrm{a}$ & $29,2 \mathrm{a}$ & $23,4 \mathrm{a}$ & $18,5 \mathrm{a}$ & $9,0 \mathrm{a}$ \\
\hline CAP/CR/77-1 & $367 \mathrm{a}$ & $30,1 \mathrm{a}$ & 23,0 a & 18,3 a & $6,4 \mathrm{c}$ \\
\hline Bruna & 365 a & 29,8 a & $24,1 \mathrm{a}$ & 18,2 a & $8,2 \mathrm{~b}$ \\
\hline Amanda & 345 a & 28,9 a & 23,7 a & 19,4 a & $7,6 \mathrm{~b}$ \\
\hline 10Y3104-1 & $290 \mathrm{~b}$ & $23,5 \mathrm{~b}$ & $22,0 \mathrm{~b}$ & 16,4 a & $6,8 \mathrm{c}$ \\
\hline Isabela & $245 \mathrm{~b}$ & $25,4 \mathrm{~b}$ & $20,0 \mathrm{~b}$ & 18,6 a & $5,9 \mathrm{c}$ \\
\hline CV. (\%) & 9,4 & 7,9 & 4,4 & 5,8 & 5,2 \\
\hline
\end{tabular}




\begin{tabular}{lccccc}
\hline 10Y3164-2 & $418 \mathrm{a}$ & $30,8 \mathrm{a}$ & $22,8 \mathrm{~b}$ & $19,6 \mathrm{c}$ & $9,1 \mathrm{c}$ \\
10Y3090-2 & $410 \mathrm{a}$ & $30,0 \mathrm{a}$ & $23,6 \mathrm{a}$ & $21,1 \mathrm{~b}$ & $10,0 \mathrm{~b}$ \\
Bruna & $398 \mathrm{a}$ & $28,5 \mathrm{~b}$ & $22,0 \mathrm{~b}$ & $18,2 \mathrm{~d}$ & $9,1 \mathrm{c}$ \\
SVR-2005 & $391 \mathrm{a}$ & $28,0 \mathrm{~b}$ & $22,1 \mathrm{~b}$ & $23,2 \mathrm{a}$ & $9,0 \mathrm{c}$ \\
Cristal & $386 \mathrm{~b}$ & $29,0 \mathrm{~b}$ & $23,9 \mathrm{a}$ & $20,0 \mathrm{c}$ & $9,0 \mathrm{c}$ \\
Coral & $377 \mathrm{~b}$ & $26,8 \mathrm{c}$ & $24,8 \mathrm{a}$ & $19,9 \mathrm{c}$ & $13,7 \mathrm{a}$ \\
\hline CV. (\%) & 8,0 & 8,1 & 4,0 & 3,8 & 9,0 \\
\hline
\end{tabular}

*Médias seguidas da mesma letra na coluna não diferem entre si pelo teste de Scott-Knott a 5\% de probabilidade

Com relação a massa fresca por planta (Tabela 1) e produtividade os genótipos foram alocados em dois grupos, sendo que os que apresentaram melhores resultados foram 'Vanda' (400 g planta $^{-1}$ e 49,1 t ha ${ }^{-1}$ ), 'CAP/CR/77-1' (367 g planta ${ }^{-1}$ e
47,9 t ha ${ }^{-1}$ ), 'Bruna' (365 g planta ${ }^{-1}$ e 44,8 t ha $^{-1}$ ) e 'Amanda' (345 g planta $^{-1}$ e 42,3 t $\mathrm{ha}^{-1}$ ), sem, contudo, diferirem entre si; e os genótipos Isabela e 10Y3104-1 apresentaram os menores rendimentos (Figura 1).

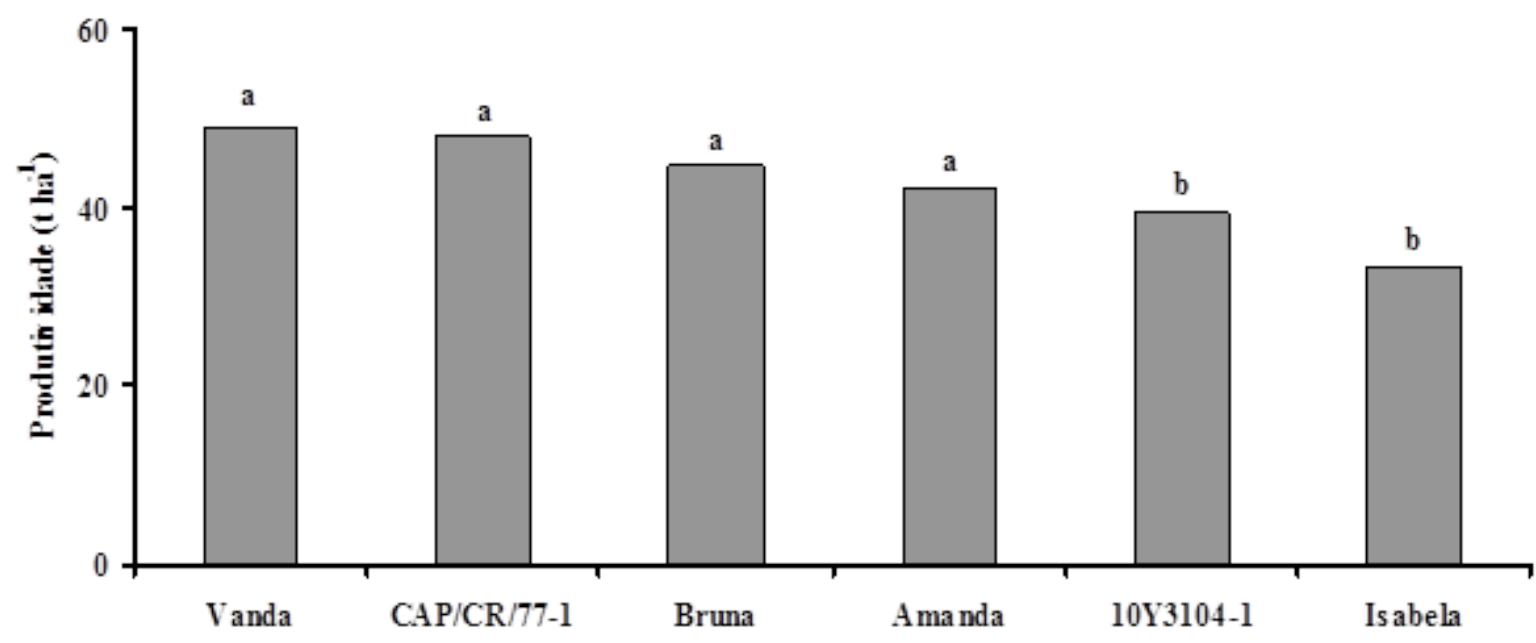

Figura 1. Produtividade de genótipos de alface crespa cultivadas no Submédio do Vale do São Francisco. Médias seguidas pela mesma letra não diferem entre si, pelo teste de Scott-Knott $(\mathrm{p} \leq 0.05$, C.V. $=9,4 \%$ ). Petrolina - PE, 2013.

No ano de 2014 os genótipos 10Y3164-2 (418 g planta $^{-1}$ e 51,5 t ha-1), 10Y3090-2 (410 g planta $^{-1}$ e 50,4 t ha ${ }^{-1}$ ), Bruna (398 g planta ${ }^{-1}$ e 48,9 t ha $^{-1}$ ) e SVR-2005 (391 g planta $^{-1}$ e 48,2 t ha $^{-1}$ ) (Tabela 1, Figura 2) sobressairam-se com maiores massass frescas por planta e produtividade, e os menores valores obtidos pelos genótipos Cristal e Coral. 


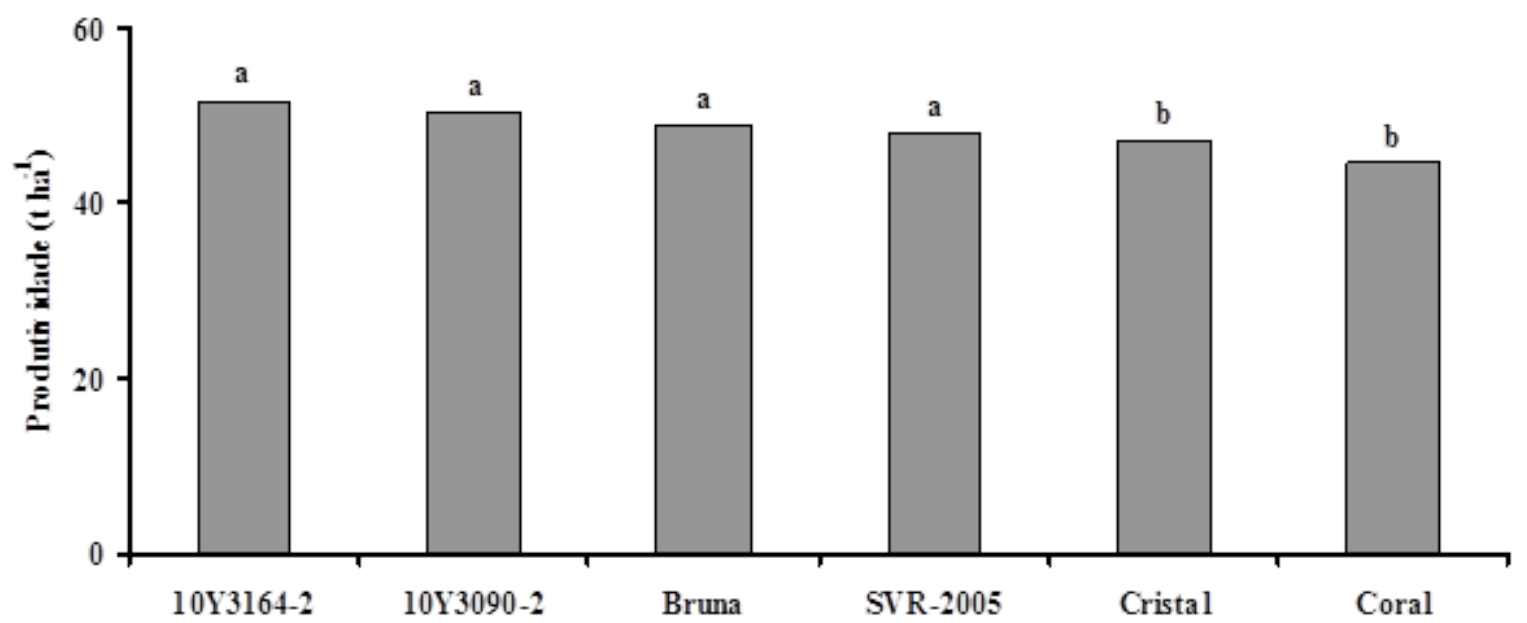

Figura 2. Produtividade de genótipos de alface crespa cultivadas no Submédio do Vale do São Francisco. Médias seguidas pela mesma letra não diferem entre si, pelo teste de Scott-Knott ( $\mathrm{p} \leq 0.05, \mathrm{C} . \mathrm{V} .=8,4 \%$ ). Petrolina - PE, 2014.

Suinaga et al. (2013) obtiveram para as cultivares Vanda e Verônica massa fresca de 776 e $682 \mathrm{~g} \mathrm{planta}^{-1}$, enquanto Lédo et al. (2000) verificaram para diferentes cultivares de alfaces crespas matérias frescas variando entre 286 e 373 g e produtividade entre 38,1 e $49,8 \mathrm{t}$ $\mathrm{ha}^{-1}$.

Valores inferiores aos obtidos no presente trabalho são informados por Araújo et al. (2007) que verificaram massa fresca por planta variando entre 136,7 e 157,3 g planta ${ }^{-1}$ e produtividade entre 21,6 a 25,2 $\mathrm{t} \mathrm{ha}^{-1}$.

Os resultados obtidos pelos genótipos mais produtivos podem ser justificados pela interação genótipo e ambiente. Isso porque, as plantas de cada cultivar respondem de maneira distinta aos fatores ambientais (SILVA et al., 2000), salientando Echer et al. (2001), que a escolha criteriosa da cultivar é decisiva para o sucesso do sistema de cultivo adotado afirma que a cultura é adaptada a temperaturas amenas, sendo que a ideal para 0 desenvolvimento está faixa de 15,5 e $18,3{ }^{\circ} \mathrm{C}$, apesar de tolerar temperaturas entre 26,6 a 29,4 ${ }^{\circ} \mathrm{C}$.

A alface é uma cultura adaptada a temperaturas amenas. Nesse quesito as temperaturas médias de 24,1 e $22,2{ }^{\circ} \mathrm{C}$, com mínima em 19,1 e $17,2{ }^{\circ} \mathrm{C}$ e máxima de 30,3 e $27,9^{\circ} \mathrm{C}$, umidade relativa de 59,8 e $61,4 \%$ e baixa precipitação acumulada nos períodos de 10 e 9,9 mm ocorridas nos anos de 2013/2014, apesar de não satisfazerem plenamente as condições ideais para cultivo de acordo com Sanders (2017), não se mostraram limitantes em função das boas massas frescas por planta e produtividades alcançadas.

Outro fato que pode ser verificado é que maiores massa fresca por planta e produtividade foram verificadas em 2014, quando os valores de temperaturas foram inferiores quando comparado a 2013, demonstrando tratar-se de uma cultura melhor adaptada a condições de temperaturas amenas, corroborando com as afirmações de que a cultura é bastante sensível a condições adversas de temperatura, produzindo melhor nas épocas mais frias do ano (OLIVEIRA et al., 2004).

O número de folhas é de grande importância tanto para o produtor, pois indica a adaptação do material genético ao ambiente, como para a comercialização. Nesse trabalho pode-se verificar que as médias de número de folhas nos genótipos, em 2013, variaram entre 23,5 e 30,1 folhas planta $^{-1}$, em que a maior média foi observada pelos genótipos CAP/CR/77-1 (30,1), Bruna (29,8), Vanda $(29,2)$ e Amada $(28,9)$, sem diferirem entre si. Em 2014, os genótipos 10Y3164-2 e 10Y30902 com 30,8 e 30,0 folhas, respectivamente, se destacaram; com pior desempenho para o genótipo Coral com 26,8 folhas (Tabela 1).

Resultados comparavéis foram encontrados por Blat et al. (2011), que em condições de estufa climatizada (máxima de $30,6{ }^{\circ} \mathrm{C}$ e mínima de $20,4{ }^{\circ} \mathrm{C}$ ) e convencional 
(temperatura máxima de $37,0{ }^{\circ} \mathrm{C}$ e mínima de $19,8{ }^{\circ} \mathrm{C}$ ) obtiveram para diferentes cultivares, entre 21,6 e 28,9 folhas por planta, respectivamente.

De acordo com Sala \& Costa (2012), existe uma tendência no Brasil, semelhante ao ocorrido nos Estados Unidos e Europa, de se consumir as folhas de alface processadas e embaladas. Neste sentido, plantas que possuam maior número de folhas comerciais são desejáveis visando atender a esta demanda crescente de mercado.

Comportamento similar, em 2013, entre os genótipos Isabela $(20,0 \mathrm{~cm})$ e 10Y3104-1 $(22,0 \mathrm{~cm})$ foram verificados para comprimento da folha (Tabela 1). Os demais obtiveram maiores valores com variação entre 23,0 e 24,1 $\mathrm{cm}$, sem evidenciar diferenças significativas entre cultivares. Para largura de folhas verificou-se oscilação entre 16,4 cm (genótipo 10Y3104-1) e 19,4 cm (genótipo Amanda), não se observando diferenças significativas entre genótipos.

Em 2014, se verificou pequena variação no comprimento de folha, entre 22,0 e $24,8 \mathrm{~cm}$ (Tabela 1), com maiores valores obtidos pelos genótipos 10Y3090-2 (23,6 cm), Cristal $(23,9)$ e Coral $(24,8 \mathrm{~cm})$. No que se refere à largura da folha, esta oscilou entre 18,2 e 23,2 cm, com maior largura evidenciada para o genótipo SVR-2005 com 23,2 cm (Tabela 1).

As características relacionadas com 0 porte das plantas, tais como o comprimento e largura, fornecem importantes informações, pois a principal forma de acondicionamento das plantas para o transporte ocorre via caixas plásticas ou de madeira. As cultivares crespas pelas suas folhas flabeladas suportam 0 encaixamento (aproximadamente $60 \mathrm{~cm} \mathrm{x} 50$ $\mathrm{cm} \times 35 \mathrm{~cm}$ ) de até 24 a 60 unidades (SALA; COSTA, 2012).

Em 2013 se verificaram comprimentos do caule oscilando entre 5,9 e 9,0 cm, com destaque para os genótipos Isabela $(5,9 \mathrm{~cm})$, CAP/CR/77-1 (6,4 cm) e 10Y3104-1 com 6,8 cm (Tabela 1). Em 2014 se obteve valores superiores variando ente 9,0 e $13,7 \mathrm{~cm}$, onde se observou para os genótipos Coral $(13,7 \mathrm{~cm})$ e $10 \mathrm{Y3090}-2 \quad(10,0 \mathrm{~cm})$ os maiores comprimentos (Tabela 1).
Santos et al. (2009) obtiveram médias de comprimento do caule para alface crespa variando entre 5,2 e 24,8 cm. Os menores comprimentos de caule foram observados nas cultivares Vanda e Isabela, com 5,2 e 5,3 cm, respectivamente. As cultivares Veneranda, Verônica, Simpson Elite e Vera, apresentaram valores superiores a Vanda e Isabela, com caules variando de 7,4 a 7,9 cm.

Menores comprimentos de caule são desejáveis, tanto sob o ponto de vista comercial, pois afeta a qualidade final do produto, bem como com relação a resistência do material ao florescimento prematuro. Quanto menor o caule, melhor qualidade na comercialização e resistência do material ao florescimento. O que se observa na prática, é que caules com comprimento entre 5,0 a $6,0 \mathrm{~cm}$ seriam os mais adequados, sendo aceitáveis até o patamar de 9,0 a $10 \mathrm{~cm}$ e inaceitáveis ou menos recomendados para comercialização acima disto RESENDE et al., 2010). Nesse contexto, somente o genótipo Coral com 13,7 $\mathrm{cm}$ não atenderia os requisitos comerciais.

Não foi verificado pendoamento entre os genótipos estudados, por ocasião da colheita. O processo de pendoamento precoce está relacionado à antecipação do ciclo reprodutivo, associado a dias longos e altas temperaturas (SILVA et al., 1999).

Temperaturas elevadas estimulam o pendoamento, que é intensificado à medida que essa aumenta, sendo uma característica indesejável, já que inviabiliza o produto para comercialização (LUZ et al., 2009).

Nas condições ambientais, no período em que se desenvolveu o experimento se constatou médias de temperatura máxima do ar de 30,0 ${ }^{\circ} \mathrm{C}$ (2013) e $27,0{ }^{\circ} \mathrm{C}$ (2014). Segundo Duarte et al. (1992) a temperatura máxima tolerável fica em torno de $30{ }^{\circ} \mathrm{C}$ para a maioria das cultivares. Pelos resultados obtidos pode-se concluir que esses valores atenderam às exigências das cultivares em função da ausência de pendoamento apresentada, mostrando-se perfeitamente adaptadas.

O uso da técnica de correlações canônicas é apropriada para estimar as relações entre dois grupos de características agronômicas primárias e secundárias de produção e/ou 
fisiológicas, morfológicas e de qualidade, podendo avaliar relações entre estas, de forma a auxiliar na seleção de um ideótipo de planta mais adequada às exigências climáticas na qual foi submetida (SANTOS et al., 1994).

Nesse contexto e de acordo com a Tabela 2, a análise de correlação canônica indicou 0 estabelecimento de dois pares canônicos, não se observando efeito significativo para o ano de 2013. Não obstante a significância não alcançada pelo primeiro par canônico em 2013, esta foi de $p=0,14$, ou seja, há probabilidade de $86 \%$ que esse evento ocorra. No caso especifico, a produtividade comercial $(0,9878)$ foi mais expressiva e estaria associada ao maior comprimento $(0,8480)$ e número de folhas $(0,7158)$, assim como ao comprimento do caule $(0,7215)$, que seriam aceitáveis até o patamar de 9,0 a $10 \mathrm{~cm}$ para comercialização. Portanto, as análises fundamentadas nas correlações canônicas ratificaram o resultado já encontrado na análise estatística anterior.

Tabela 2. Correlações e pares canônicos estimados entre caracteres relacionados à produtividade (Grupo I) e caracteres morfológicos (Grupo II) de genótipos de alface. Petrolina - PE, 2013/2014.

\begin{tabular}{|c|c|c|c|}
\hline \multicolumn{4}{|c|}{ Ano de 2013} \\
\hline \multirow{2}{*}{ Grupo } & \multirow{2}{*}{ Características } & \multicolumn{2}{|c|}{ Par canônico } \\
\hline & & $1^{0}$ & $2^{\circ}$ \\
\hline \multirow{2}{*}{ I } & Produtividade comercial & 0,9878 & 0,1559 \\
\hline & Massa fresca por planta & 0,9737 & 0,2274 \\
\hline \multirow{4}{*}{ II } & Número de folhas & 0,7158 & $-0,4709$ \\
\hline & Comprimento da folha & 0,8480 & 0,5234 \\
\hline & Largura da folha & $-0,1765$ & $-0,2286$ \\
\hline & Comprimento do caule & 0,7215 & $-0,5547$ \\
\hline $\mathrm{R}$ & & $0,53^{\text {ns. }}$ & $0,40^{\mathrm{ns}}$ \\
\hline \multicolumn{4}{|c|}{ Ano de 2014} \\
\hline \multirow{2}{*}{ I } & Produtividade comercial & 0,4291 & 0,9032 \\
\hline & Massa fresca por planta & 0,6638 & 0,7479 \\
\hline \multirow{4}{*}{ II } & Número de folhas & 0,4767 & 0,3049 \\
\hline & Comprimento da folha & $-0,1920$ & 0,5611 \\
\hline & Largura da folha & 0,2215 & 0,2597 \\
\hline & Comprimento do caule & $-0,7737$ & 0,6096 \\
\hline $\mathrm{R}$ & & $0,54^{* *}$ & $0,30^{\mathrm{ns}}$ \\
\hline
\end{tabular}

Significativo a $5 \%\left({ }^{*}\right)$ e $1 \%$ de probabilidade $\left(^{* *}\right)$ e não significativo (ns) pelo teste de F.

Para o ano de 2014 observou-se efeito significativo do primeiro par canônico, sendo determinante para uma maior massa fresca por planta $(0,6638)$ o maior número de folhas $(0,4767)$. Outro fato relevante é o efeito negativo limitante do comprimento do caule (0,7737) na recomendação dos genótipos avaliados nesse ano, no caso da cultivar Coral a qual teve sua recomendação inviabilizada por esse fato. O maior de folhas foi determinante na escolha do genótipo e é de grande importância tanto para o produtor, pois indica a boa adaptação do material genético ao ambiente, como também para a comercialização do produto. Nesse contexto os resultados obtidos na analise canônica contextualiza os anteriores reafirmando a recomendação dos genótipos que melhor se adaptaram as condições do Submédio do Vale do São Francisco.

\section{CONCLUSÃO}

Nos dois anos de cultivo em termos de produtividade e qualidade comercial (comprimento do caule) da alface crespa, podese concluir para as condições irrigadas do Submédio do Vale do São Francisco ser viável 
seu cultivo e que as cultivares Vanda, Bruna, Amanda são as mais recomendadas para o plantio e os genótipos não comerciais CAP/CR/77-1, 10Y3164-2, 10Y3090-2 e SVR2005 são opções de plantio para futuros cultivos.

\section{REFERÊNCIAS}

ARAÚJO, W.F.; TRAJANO, E.P.; RODRIGUES NETO, J.R.; MOURÃO JÚNIOR, M.; PEREIRA, P.R.V.S. Avaliação de cultivares de alface em ambiente protegido em Boa Vista, Roraima, Brasil. Acta Amazônica, v. 37, n. 2, p. 299-302, 2007.

BLAT, S.F.; SANCHEZ, S.V.; ARAÚJO J.A.C.; BOLONHEZI, D. Desempenho de cultivares de alface crespa em dois ambientes de cultivo em sistema hidropônico. Horticultura Brasileira, v. 29, n. 1, p. 135138, 2011.

BOAS, R.L.V.; PASSOS, J.C.; FERNANDES, D.M.; BULL, L.T.; CEZAR, V.R.S.; GOTO, R. Efeito de doses e tipos de composto orgânicos na produção de alface em dois solos sob ambiente protegido. Horticultura Brasileira, v. 22, n. 1, p. 28-34, 2004.

COMETTI, N.N.; MATIAS, G.C.S.; ZONTA, E.; MARY, W.; FERNANDES, M.S. Compostos nitrogenados e açúcares solúveis em tecidos de alface orgânica, hidropônica e convencional. Horticultura Brasileira, v. 22, n. 4, p. 748-753, 2004.

CRUZ, C.D.; REGAZZI, A.J. Modelos biométricos aplicados ao melhoramento genético. 2.ed. rev. Viçosa: UFV. 2001. 390p.

DUARTE, R.L.R.; SILVA, P.H.S.; RIBEIRO, V.Q. Avaliação de cultivares de alface nos períodos chuvosos e secos em Terezina-PI. Horticultura Brasileira, v. 10, n. 2, p. 106108, 1992.

ECHER, M.M.; SIGRIST, J.M.M.; GUIMARÃES, V.F.; MINAMI, K.
Comportamento de cultivares de alface em função do espaçamento. Revista de Agricultura, v. 76, n. 2, p. 267-275, 2001.

FILGUEIRA, F.A.R. Novo Manual de Olericultura: Agrotecnologia moderna na produção e comercialização de hortaliças. Viçosa: UFV. 2008. 421p.

GUALBERTO, R.; OLIVEIRA, P.S.R.; GUIMARÃES, A.M. Adaptabilidade e estabilidade fenotípica de cultivares de alface do grupo crespa, em cultivo hidropônico. Horticultura Brasileira, v. 27, n. 1, p. 7-11, 2009.

HORTBRASIL. Alface na CEAGESP paulistana. Disponível em: <http://www. hortibrasil.org.br/jnw/index.php?option=com_c ontent\&view=article\&id=1132:alface-naceagesp-paulistana i\&catid=50: comercializacao\&Itemid=82> . Acesso em: 23 set. 2013.

IBGE - Instituto Brasileiro de Geografia e Estatística. Censo Agropecuário de 2006. Disponível em: <http://www.ibge.gov.br>. Acesso em: 6 mai. 2016.

LÉDO, F.J.S.; SOUSA, J.A.; SILVA, M.R. Desempenho de cultivares de alface no Estado do Acre. Horticultura Brasileira, v.18, n. 3, p. 225-228, 2000.

LUZ, A.O.; JÚNIOR SEABRA, S.; SOUZA, S.B.S.; NASCIMENTO, A.S. Resistência ao pendoamento de genótipos de alface em ambientes de cultivo. Agrarian, v. 2, n. 6, p. 71-82, 2009.

OLIVEIRA, A.C.B.; SEDIYAMA, M.A.N.; PEDROSA, M.W.; GARCIA, N.C.; GARCIA, S.L.R. Divergência genética e descarte de variáveis em alface cultivada sob sistema hidropônico. Acta Scientiarum: agronomy, v. 26, n. 2, p. 211-217, 2004.

PUIATTI, M.; FINGER, F.L. Fatores climáticos. In: FONTES, P.C.R. (Ed.). 
Olericultura - teoria e prática. Viçosa: Editora UFV, 1 ed. 2005. p. 17-38.

RESENDE, G.M.; ALVARENGA, M.A.R.; YURI J.E.; SOUZA, R.J. Yield and postharvest quality of winter growing crisphead lettuce as affected by doses of nitrogen and molybdenum. Horticultura Brasileira, v. 28, n. 4, p. 441445, 2010.

RODRIGUES, I.N.; LOPES, M.T.G.; LOPES, R.; GAMA, A.S.; MILAGRES, C.P. Desempenho de cultivares de alface na região de Manaus. Horticultura Brasileira, v. 26, n. 4, p. 524-527, 2008.

RYDER, E.J. Lettuce, endive and chicory. New York: CABI Publishing. 1999. 208p.

SALA, F.C.; COSTA, C.P. Retrospectiva e tendência da alfacicultura brasileira. Horticultura Brasileira, v. 30, n. 2, p. 187194, 2012.

SANDERS, D.C. Lettuce production. Disponível em: <http://www.ces.ncsu.edu/hil /hil-11.html> Acesso em: 23 jan. 2017.

SANTOS, C.A.F.; CAVALCANTI, J.; PAINI, J.N.; CRUZ, C.D. Correlações canônicas entre componentes primários e secundários da produção de grãos em guandu (Cajanus cajan (L.) Millsp). Ceres, v. 41, n. 236, p. 459-464, 1994.

SANTOS, C,L.; JUNIOR SEABRA, S.; LALLA, J.G.; THEODORO, V.C.A.; NESPOLI, A. Desempenho de cultivares de alface tipo crespa sob altas temperaturas em Cáceres-MT. Agrarian v. 2, n. 3, p.87-98, 2009.

SANTOS, H.G.; JACOMINE, P.K.T.; ANJOS, L.H.C.; OLIVEIRA, V.A.; OLIVEIRA, J.B.;
COELHO, M.R.; LUMBRERAS, J.F.; CUNHA, T.J.F. (Eds.) Sistema brasileiro de classificação de solos. 2. ed. Rio de Janeiro: Embrapa Solos. 2006. 306p.

SILVA, E.C.; LEAL, N.R.; MALUF, W.R. Avaliação de cultivares de alface sob altas temperaturas em cultivo protegido em três épocas de plantio na região Norte Fluminense. Ciência e Agrotecnologia, v. 23, n. 3, p. 491499, 1999.

SILVA, V.F.; BEZERRA NETO, F.; NEGREIROS, M.Z.; PEDROSA, J.F. Comportamento de cultivares de alface em diferentes espaçamentos sob temperatura e luminosidade elevadas. Horticultura Brasileira, v. 18, n. 3, p. 183-187, 2000.

SUINAGA, F.A.; BOITEUX, L.S.; CABRAL, C.S.; RODRIGUES, C.S. Desempenho produtivo de cultivares de alface crespa. Brasília, DF: Embrapa, 15p. 2013. (Boletim de Pesquisa e Desenvolvimento/Embrapa Hortaliças, 89).

TEIXEIRA, A.H.C. Informações agrometeorológicas do Pólo Petrolina, PE/Juazeiro - 1963 a 2009. Petrolina: Embrapa Semiárido. 21p. 2010. (Embrapa Semiárido. Documentos, 233).

TRANI, P.E. Calagem e adubação para hortaliças sob cultivo protegido. Artigo em Hypertexto. Disponível em: <http://www.infobibos.com/Artigos/2007_1/cp/ index.htm>. Acesso em: 11 abr. 2016.

TRANI, P.E.; TIVELLI, S.W.; PURQUERIO, L.F.V.; AZEVEDO FILHO, J.A. Informações tecnológicas - Alface (Lactuca sativa L.). Campinas: IAC. Disponível em: $<$ http://www.iac.sp.gov.br/infotecnologicas.php $>$ Acesso em: 18 de outubro 2016. 